\title{
Interfacial Adaptation of an Epoxy-Resin Sealer and a Self-Etch Sealer to Root Canal Dentin Using the System B or the Single Cone Technique
}

\author{
Bruno Cavalini CAVENAGO \\ Marco Antonio Hungaro DUARTE \\ Ronald ORDINOLA-ZAPATA \\ Marina Angélica MARCIANO \\ Aldo Enrique del CARPIO-PEROCHENA \\ Clovis Monteiro BRAMANTE
}

Department of Operative Dentistry, Dental Materials and Endodontics, Bauru Dental School, USP - Univeristy of São Paulo, Bauru, SP, Brazil

\begin{abstract}
The aim of this laboratory study was to compare the interfacial adaptation of an epoxy-resin and a self-etch sealer in mesial root canals of mandibular molars filled using the System-B/Elements Obturation Unit. Sixty mesial root canals of mandibular molars were prepared using the K3 rotary system up to 35.04 instrument and then filled with the aid of the System-B/Elements Obturation Unit using either gutta-percha/ThermaSeal Plus $(n=15)$ or Resilon/Real Seal SE $(n=15)$. The single cone technique using both materials was used as control. The sealers were stained with Rhodamine B dye and the teeth were filled and sectioned at 2, 4 and $6 \mathrm{~mm}$ from the apex. The interfacial marginal adaptation of sealers was evaluated using confocal microscopy. Statistical analyses were performed by the Kruskall-Wallis test $(\alpha=0.05)$. In general, microscopic analysis showed a quite regular gap distribution pattern at sealer-dentin interfaces, mainly for the two groups filled with Real Seal SE. This means that both nonbonding root-filling groups (ThermaSeal Plus) showed significantly higher amount of gap-free regions regardless of the filling technique $(\mathrm{p}<0.05)$. Better marginal adaptation was obtained with gutta-percha and epoxy resin-based sealer using either the system B or the single cone technique.
\end{abstract}

Key Words: confocal laser scanning microscopy, dentin, root canal filling, gutta-percha, Resilon.

\section{INTRODUCTION}

The introduction of the dentin adhesiveness technology specific for Endodontics was based on the possibility of achieving the ideal monoblock root-filling. The monoblock concept is theoretically related to a genuine gap-free solid filling mass that is able to produce a real fluid-tight seal and also improve the fracture resistance of the root (1). However, laboratory results have shown that it is a real challenge to produce a reliable monoblock root filling $(1,2)$ because of some factors: (a) the heterogeneous composition of root dentin as well as its complex anatomical configuration that includes fins, extensions and isthmuses; (b) the high frequency of sclerotic dentin in the apical third of the root canal; and (c) the great amount of hard tissue debris accumulated in the canal space. Moreover, it is worth noting that long narrow root canals have a true unfavorable geometry for resin bonding because the $\mathrm{C}$-factor of adhesive filling materials is highly unfavorable for an effective bonding in this scenario (1). In a remarkable review, Schwartz (2) highlighted the critical conditions for an optimal intraradicular bonding due to the above-mentioned reasons. Considering these factors and limitations, the effectiveness of the adhesive root fillings is under ongoing scientific scrutiny and, by restrict experimental standpoint, this suboptimal condition has been shown in several studies (1-3). Many filling techniques have been developed in the search for a hermetic root canal filling. Thermoplasticization techniques usually produce a higher percentage of gutta-percha than sealer, but at the apical level, there is a decrease of the percentage area

Correspondence: Bruno Cavalini Cavenago, Alameda Dr. Octávio Pinheiro Brisolla, 9-75, 17012-901 Bauru, SP, Brasil. Tel.: +55-14-3235-8344. Fax: +55-14-3224-2788. e-mail: brunocavenago@usp.br 
of gutta-percha and an increase of sealer (4).

This way, alternative strategies and new adhesive sealer generations have been developed to circumvent these limitations, a new version of low-viscosity methacrylate sealer for endodontic purposes - based on the self-adhesive cement concept - was introduced with the promise of optimizing the clinical performance of the filling procedure due to a simplified application. RealSeal self-etch sealer (Epiphany SE; Pentron Clinical Technologies LLC, Wallingford, CT, USA) is claimed to reduce the application steps, thus becoming a more user-friendly material. The present study was designed to assess the interfacial quality between RealSeal SE/ Resilon and the surrounding dentin in teeth filled by either the continuous wave of condensation or the single-cone technique. The conventional epoxy resin/ gutta-percha root filling was employed as a reference for comparison and confocal laser scanning microscopy (CLSM) was used as the analytical tool. The null hypotheses tested were: 1 . there is no difference in the quality of the interfacial adaptation in root canals filled with RealSeal SE and epoxy sealer; and 2. root filling technique has no influence on the quality of the interfacial adaptation.

\section{MATERIAL AND METHODS}

\section{Sample Selection and Root Canal Preparation}

The ethics committee of the institution in which the study was carried out approved the use of extracted teeth for research purposes (CEP 122-2009). Sixty mandibular molars with patent mesial canals with a curvature degree ranging from $15^{\circ}$ to $30^{\circ}$ were included (5). Standard access cavities were made and a size 10 $\mathrm{K}$-file was introduced in each canal until it could be seen through the apical foramen and the length was measured. Working length (WL) was established by subtracting $1 \mathrm{~mm}$ from that length. The root canals were prepared using K3 NiTi rotary instruments (SybronEndo, Orange, CA, USA). The final preparation had a 0.04 taper with a diameter of $0.35 \mathrm{~mm}$ at $1 \mathrm{~mm}$ from the apical foramen. All canals were irrigated between each file with $0.5 \mathrm{~mL}$ of freshly prepared $2.5 \% \mathrm{NaOCl}$. After instrumentation, the canals were irrigated with $2 \mathrm{~mL}$ of $2.5 \% \mathrm{NaOCl}$ for $1 \mathrm{~min}$ using passive ultrasonic irrigation with an intermittent flush technique. This procedure was repeated 3 times. The smear layer was removed with $3 \mathrm{~mL}$ of $17 \%$ EDTA for $3 \mathrm{~min}$ and $3 \mathrm{~mL}$ flush of bi-distilled water was used as the final rinse.

After preparation, the sample was randomly assigned to 4 experimental groups ( $\mathrm{n}=15)$ using an open source random number generator (http://www.openepi. com/Menu/OpenEpiMenu.htm).

\section{Root Canal Filling}

ThermaSeal Plus (Dentsply Tulsa Dental, Tulsa, OK, USA) or RealSeal SE (Sybron Endo) were mixed with Rhodamine dye to an approximate concentration of $0.1 \%$ in order to allow confocal microscopy analysis (6). In group 1, Resilon/RealSeal SE (SybronEndo) was used by the continuous wave of condensation technique. The tip of a prefitted 35.04 Resilon cone was trimmed back until tug-back was achieved at WL. A 0.06 plugger that penetrated to within $4 \mathrm{~mm}$ of the WL was selected. The System B Elements Obturation Unit was preset to $150^{\circ} \mathrm{C}$ during the condensation of the primary Resilon cone (down-pack). Resilon at the apical level was condensed using Buchanan hand pluggers (SybronEndo). Using the extruder handpiece of the Elements Obturation Unit, the backfill procedure was performed. In group 2, gutta-percha and ThermaSeal Plus were used in the same manner described for group 1, but the System B was set at $200^{\circ} \mathrm{C}$ and gutta-percha was used for the backfill.

In group 3, a 35.04 Resilon cone with an adequate tugback at the apical primary fit was selected. The cone was coated with RealSeal SE sealer and inserted into the canal that was previously filled with sealer using a lentulo spiral to the WL. Excess material was seared off and condensed with a plugger $1 \mathrm{~mm}$ below the canal orifice. In group 4, gutta-percha 35.04 master cone and Thermaseal Plus were used in the same manner described for group 3.

In order to create an immediate coronal seal, specimens in groups 1 and 3 were light-cured for $40 \mathrm{~s}$ with a Coltolux LED curing light (Coltene Whaledent Product, Cuyahoga Falls, OH, USA).

\section{Sectioning, Isthmus Classification and CLSMAnalysis}

Specimens were horizontally sectioned at 2, 4 and $6 \mathrm{~mm}$ from the apex using a $0.3 \mathrm{~mm}$ Isomet saw (Isomet; Buehler, Lake Buff, IL, USA). Three slices per root were created, resulting in 45 slices per group. Only the coronal face of each slice was examined. A standard metallographic procedure (polishing with 200-, 300-, 400-, 600-grit SiC paper and 3- $\mu \mathrm{m}$ diamond 
paste) was employed on dentin surface to prepare them for the microscopic analysis, and the specimens were examined under a stereomicroscope (Stemi 2000C; Carl Zeiss, Jena, Germany).

Images were used to measure the perimeter of the root canals including the two mesial canals and the isthmus, if present, using the Axiovision software (Carl Zeiss). The presence of isthmuses at the studied levels was also registered in 5 categories according to Teixeira et al. (7) and its balance among the experimental groups was verified systematically.

In order to evaluate the interfacial adaptation, confocal images $(1024 \times 1024$ pixels $)$ were recorded at $\times 100$ magnification using the fluorescent mode (Leica TCS-SPE; Microsystems GmbH, Mannheim, Germany). All sealer/dentin regions were evaluated and the interface integrity was determined as described previously $(8,9)$ by calculating the ratio between the total sealer/dentin interface and the gap-containing regions. The operator who made the measurements was blinded as to which samples were matched to which materials. All measurements were repeated twice to ensure reproducibility.

\section{Statistical Analysis}

The preliminary analysis of the raw pooled data did not show a bell-shaped distribution by the
D'Agostino and Person normality test. Further statistical analysis was performed using nonparametric methods. The Kruskal-Wallis test and post-hoc analysis were performed using Dunn's multiple comparisons. The distribution of isthmuses was evaluated using the Kruskal-Wallis test. The alpha-type error was set at 0.05 and Prisma 5.0 (GraphPad Software Inc., La Jolla, CA, USA) was used as the analytical tool.

\section{RESULTS}

The group-by-location interaction was not significant $(p>0.05)$, which means that the group comparisons were not dependent upon the crosssection level. As a consequence, all data were pooled to provide a single median, averaging 45 sections per group. Moreover, the Kruskal-Wallis test revealed that isthmuses distribution among the experimental groups was well-balanced ( $\mathrm{p}>0.05)$ (Fig. 1).

Overall, CLSM analysis showed a quite regular gap distribution pattern between sealer-dentin interfaces, mainly for the adhesive root fillings groups. This means that both nonbonding root-fillings showed a significantly larger number of gap-free regions $(p<0.05)$ regardless of the filling technique.

There were not significantly more gap-free regions in the System B versus Single-cone root fillings using both sealers $(p>0.05)$. Figure 2 shows the median,

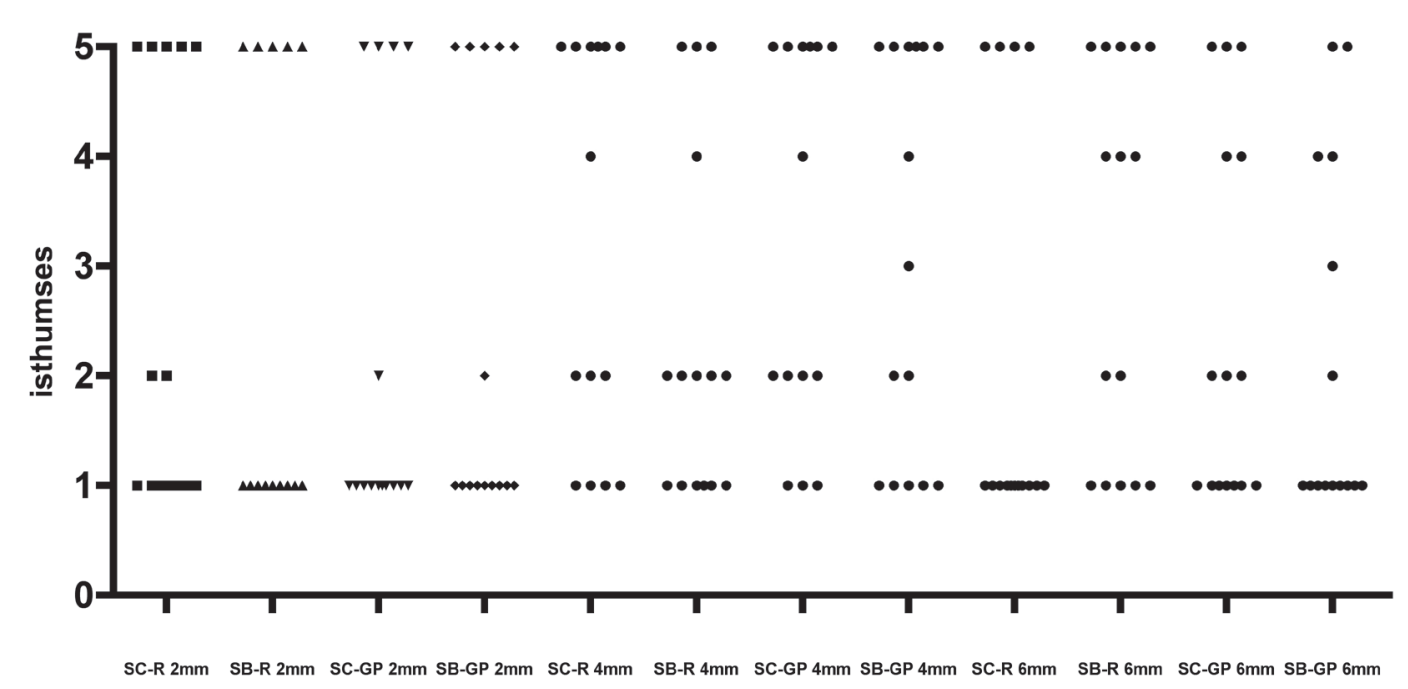

Figure 1. Distribution of isthmuses in five categories at 2, 4 and $6 \mathrm{~mm}$ level from the apex according to Teixeira et al. (7). Type I was defined as either 2 or 3 canals with no notable communication. Type II was defined as 2 canals with a definite connection between the 2 main canals. Type III differs from Type II due to the presence of 3 canals instead of 2 . In the Type IV, the canals extended to the isthmus area. Type V was defined as a true connection or corridor throughout the section. SC: Single Cone; SB: System B; R:Resilon; GP: gutta-percha. 


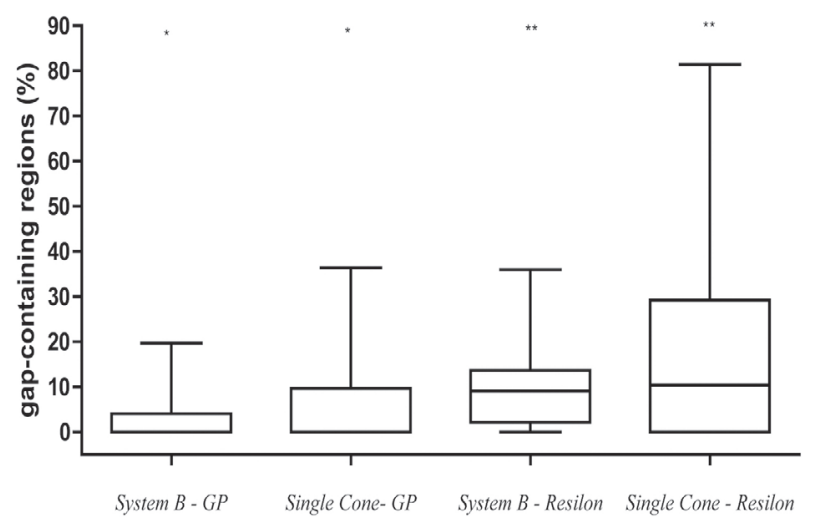

Figure 2. Box plots of the percentage of the gap-contain regions. Different symbols represent significant differences $(p<0.05)$. minimal, and maximal values of the data about the quality of interfacial adaptation in each experimental group. Figures 3 and 4 display representative CLSM images of root canal filling/dentin interfaces.

\section{DISCUSSION}

The first null hypothesis tested was rejected since RealSeal SE showed a significantly larger number of gap-containing regions than the epoxy resin sealer root fillings. This result outlines that quality of the interfacial adaptation is compromised in adhesive root-fillings due to the high and regular gap-distribution pattern between sealer-dentin interfaces. It is worth noting that sealability
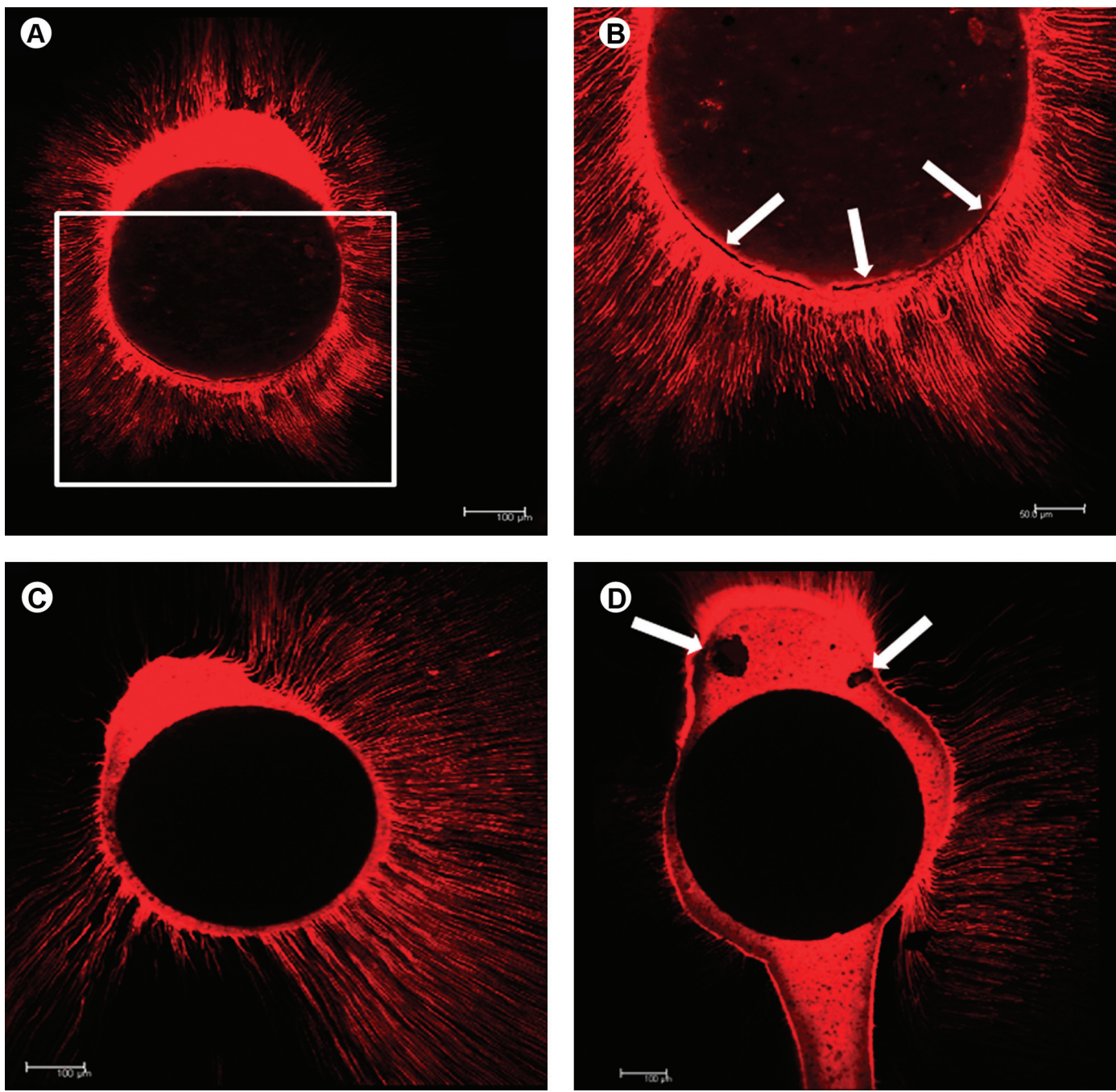

Figure 3. Representative confocal image of a canal filled with RealSeal SE/single-cone technique (A). A magnification showing a typical gap region between the filling and the root canal walls (white arrows in B). Representative images of canals filled with ThermaSeal/ single-cone technique (C and D). Voids are evident (white arrows) (D). 
is prone to be dependent on the quality of the interfacial adaptation (9). The present experimental results are relevant because gap-containing regions can increase potential microbial leakage (9). Therefore, the smaller the number of gap-containing regions, the better the performance of the root filling tends to be. It means that one of the goals of the filling procedure must be to maximize gap-free sealer-dentin interfaces.

The more accepted explanation for the interfacial failures in adhesive root fillings is related to the volumetric shrinkage of the sealer during the polymerization (1,2,911). Another explanation of the results found in the adhesive fillings herein could be the natural presence of water in the root dentin that promotes the chemical hydrolysis of ester bonds in low-viscosity methacrylate resin-based root canal sealers (12). Moisture degree is recognized as one of the most important factors affecting degree of conversion (DC) of the resin-based materials (12). Results provided by micro-Raman spectroscopy suggest that water within the dentin tubules can inhibit the polymerization of the acidic monomers (12). Wu et al. (13) reported that drying of root canals with paper points followed by $95 \%$ ethanol resulted in drier dentin and favored the DC of RealSeal SE. The authors speculated that ethanol might be able to remove excess water in dentin to prevent suboptimal resin polymerization, which represents sites of leakage that could decrease resin-dentin bond durability.

As in previous studies (14-16), a high incidence of isthmuses in mandibular molars between the $2 \mathrm{~mm}$ and $6 \mathrm{~mm}$ level was found in the present investigation. The current results showed that irregular anatomy including
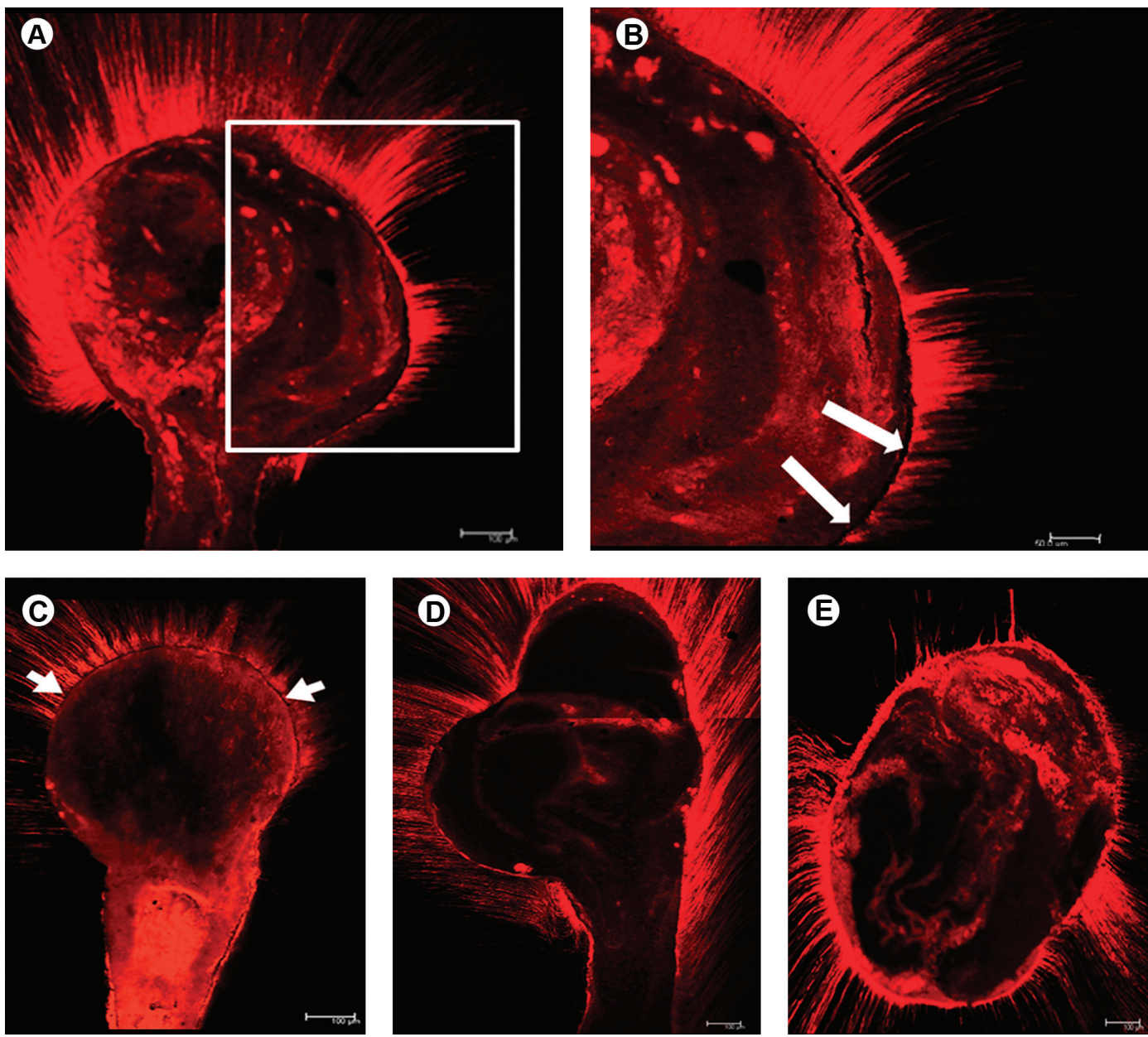

Figure 4. Representative images of the RealSeal SE/System B technique (A-C). Magnification of the interface shows a typical gap between sealer and the surrounding dentin (white arrows in B); Representative images of canals filled with ThermaSeal Plus/System B showing an adequate adaptation of the gutta-percha to the root canal walls (D-E). 
fins and isthmuses might severely affect the interfacial adaptation of RealSeal SE to root dentin using the singlecone or System B technique. Despite the reasonable success in clinical studies of methacrylate-based sealers (17), the major implication of the present laboratory study is related to the advantages of the current available technology for adhesive root fillings. The present results are also supported by previous leakage and push-out studies that found better sealability $(18,19)$ and bond strength $(20,21)$ when epoxy resin sealers were used in comparison to methacrylate resin sealers.

The quality of a given root canal filling can be assessed by radiographic and microscopic methods, as well as by microcomputed tomography $(\mu \mathrm{CT})$. This last method has the advantage to produce volumetric data. However, $\mu \mathrm{CT}$ is unable to discriminate residual organic tissue from voids or gaps in root fillings. The present study used high-contrast CLSM images because of their capacity to distinguish interfacial failures avoiding artificial gaps that could be produced after high-vacuum desiccation $(9,22)$. Furthermore, real slight gaps and failures $(<5 \mu \mathrm{m})$ can be identified and measured (9).

In this study, single-cone fillings were tested by the absence of compaction forces. The results showed that teeth filled by the single-cone technique did not have significantly more gap-containing regions than those filled by the System B technique. Thus, the root filling technique did not seem to have a significant impact on the interfacial adaptation quality observed. As such, the second null hypothesis was plainly accepted. Single-cone gutta-percha techniques performed with conventional sealers have been found to be as efficient to fill the apical third of the canal as vertical and lateral compaction technique (23). However, it is expected that a large quantity of sealer can be present in single-cone fillings in comparison with vertically compacted guttapercha or Resilon. Because methacrylate resin sealers have some degree of solubility (24), the quality of the filling in single-cone techniques may be compromised in time or the degradation could be faster when a relative soluble sealer is used in comparison with vertical compaction fillings (25).

From a practical perspective, close examination of the present results yields an interesting thought for further consideration. Despite the theoretical development achieve with the introduction of current dentin adhesive technology specific for root-fillings procedures, the simple and cost-effective nonbonding root-fillings are still closer to the ideal filling due to significantly smaller number of gap-containing interfacial areas.

\section{RESUMO}

O objetivo deste estudo laboratorial foi avaliar comparativamente a adaptação na interface obturação/dentina em canais mesiais de molares inferiores obturados com System B, tanto com guta percha/ThermaSeal Plus como com Resilon/Real Seal SE. Os canais mesiais de 60 molares inferiores foram modelados utilizando o sistema rotatório $\mathrm{K} 3$, realizando o batente apical com $\mathrm{o}$ instrumento 35,04. Em seguida os canais foram obturados com guta percha/ThermaSeal Plus ( $\mathrm{n}=15)$ e com Resilon/Real Seal $\mathrm{SE}(\mathrm{n}=15)$ por meio do System B. Obturações com a técnica do cone único utilizando os dois materiais foram empregadas como controle. Os cimentos foram corados com Rodamina $\mathrm{B}$ e os dentes obturados foram seccionados a 2, 4 e 6 mm do ápice. A adaptação da interface marginal foi avaliada utilizando a microscopia confocal. A análise estatística foi realizada empregando o teste Kruskall-Wallis $(\mathrm{p}<0,05)$. De modo geral, a análise microscópica mostrou um padrão regular na distribuição de fendas na interface cimento-dentina, principalmente para os dois grupos com cimento Real Seal SE. Sendo que os outros dois grupos (com ThermaSeal Plus), apresentaram uma quantidade significativamente menor de áreas com fendas, independentemente da técnica de obturação $(p<0,05)$. A melhor adaptação marginal foi observada quando se utilizou guta percha e o cimento à base de resina epóxica, tanto com o System B como com cone único.

\section{ACKNOWLEDGEMENTS}

This work was supported by grant (\#2009/15233-5) from the São Paulo State Research Foundation (FAPESP). The authors deny any conflict of interest.

\section{REFERENCES}

1. Kim YK, Grandini S, Ames JM, Gu LS, Kim SK, Pashley DH, et al.. Critical review on methacrylate resin-based root canal sealers. J Endod 2010;36:383-399.

2. Schwartz RS. Adhesive dentistry and endodontics. Part 2: bonding in the root canal system-the promise and the problems: a review. J Endod 2006;32:1125-1134.

3. Tay FR, Pashley DH. Monoblocks in root canals: a hypothetical or a tangible goal. J Endod 2007;33:391-398.

4. Marciano MA, Bramante CM, Duarte MAH, Delgado RJR, Ordinola-Zapata R, Garcia RB. Evaluation of single root canals filled using the lateral compaction, Tagger's Hybrid, Microseal and Guttaflow techniques. Braz Dent J 2010;21:411-415.

5. Schneider SW. A comparison of canal preparations in straight and curved root canals. Oral Surg Oral Med Oral Pathol 1971;32:271275.

6. D’Alpino PH, Pereira JC, Svizero NR, Rueggeberg FA, Pashley DH. Use of fluorescent compounds in assessing bonded resinbased restorations: a literature review. J Endod 2006;34:623-634.

7. Teixeira FB, Sano CL, Gomes BP, Zaia AA, Ferraz CC, SouzaFilho FJ. A preliminary in vitro study of the incidence and position of the root canal isthmus in maxillary and mandibular first molars. Int Endod J 2003;36:276-280.

8. Bonfante EA, Pegoraro LF, de Goes MF, Carvalho RM. SEM observation of the bond integrity of fiber-reinforced composite 
posts cemented into root canals. Dent Mater 2008;24:483-491.

9. De-Deus G, Reis C, Giorgi KD, Brandao MC, Audi C, Fidel RA. Interfacial adaptation of the Epiphany self-adhesive sealer to root dentin. Oral Surg Oral Med Oral Pathol Oral Radiol Endod 2011;111:381-386.

10. Hammad M, Qualtrough A, Silikas N. Extended setting shrinkage behavior of endodontic sealers. J Endod 2008;34:90-93.

11. Bergmans L, Moisiadis P, De Munck J, Van Meerbeek B, Lambrechts P. Effect of polymerization shrinkage on the sealing capacity of resin fillers for endodontic use. J Adhes Dent 2005;7:321-329.

12. Spencer P, Ye Q, Park J, Topp EM, Misra A, Marangos O, et al.. Adhesive/Dentin interface: the weak link in the composite restoration. Ann Biomed Eng 2010;38:1989-2003.

13. Wu WC, Shrestha D, Wei X, Ling JQ, Zhang WH, Chen J. Degree of conversion of a methacrylate-based endodontic sealer: a microRaman spectroscopic study. J Endod 2010;36:329-333.

14. Gu L, Wei X, Ling J, Huang X. A microcomputed tomographic study of canal isthmuses in the mesial root of mandibular first molars in a Chinese population. J Endod 2009;35:353-356.

15. Jung IY, Seo MA, Fouad AF, Spångberg LS, Lee SJ, Kim HJ, et al.. Apical anatomy in mesial and mesiobuccal roots of permanent first molars. J Endod 2005;31:364-368.

16. Mannocci F, Peru M, Sherriff M, Cook R, Pitt Ford TR. The isthmuses of the mesial root of mandibular molars: a microcomputed tomographic study. Int Endod J 2005;38:558-563.

17. Cotton TP, Schindler WG, Schwartz SA, Watson WR, Hargreaves KM. A retrospective study comparing clinical outcomes after obturation with Resilon/Epiphany or Gutta-Percha/Kerr sealer. J Endod 2008;34:789-797.

18. Souza SF, Bombana AC, Francci C, Goncalves F, Castellan C, Braga RR. Polymerization stress, flow and dentine bond strength of two resin-based root canal sealers. Int Endod J 2009;42:867873.

19. Paqué F, Sirtes G. Apical sealing ability of Resilon/Epiphany versus gutta-percha/AH Plus: immediate and 16-months leakage. Int Endod J 2007;40:722-729.

20. De-Deus G, Di Giorgi K, Fidel S, Fidel RA, Paciornik S. Push-out bond strength of Resilon/Epiphany and Resilon/Epiphany selfetch to root dentin. J Endod 2009;35:1048-1050.

21. Nunes VH, Silva RG, Alfredo E, Sousa-Neto MD, Silva-Sousa YTC. Adhesion of Epiphany and AH Plus sealers to human root dentin treated with different solutions. Braz Dent J 2008;19:46-50

22. Ordinola-Zapata R, Bramante CM, Graeff MS, del Carpio Perochena A, Vivan RR, Camargo EJ, et al.. Depth and percentage of penetration of endodontic sealers into dentinal tubules after root canal obturation using a lateral compaction technique: a confocal laser scanning microscopy study. Oral Surg Oral Med Oral Pathol Oral Radiol Endod 2009;108:450-457.

23. El Ayouti A, Kiefner P, Hecker H, Chu A, Lost C, Weiger R. Homogeneity and adaptation of endodontic fillings in root canals with enlarged apical preparation. Oral Surg Oral Med Oral Pathol Oral Radiol Endod 2009;108:e141-e146.

24. Resende LM, Rached-Junior FJ, Versiani MA, Souza-Gabriel AE, Miranda CE, Silva-Sousa YT, et al.. A comparative study of physicochemical properties of AH Plus, Epiphany, and Epiphany SE root canal sealers. Int Endod J 2009;49:785-793.

25. De-Deus G, Coutinho-Filho T, Reis C, Murad C, Paciornik S. Polymicrobial leakage of four root canal sealers at two different thicknesses. J Endod 2006;32:998-1001.

Received September 2, 2011 Accepted March 5, 2012 